\title{
EXPLANATION OF SYMBOLS
}

פ-Ferrara edition, 1555.

$\checkmark-M S$. Sulzberger, Jewish Theological Seminary.

מ-MS. Munich.

ל-MS. Jews' College.

-MS. Paris, Bibliothèque Nationale.

-MS. Vienna.

7-MS. Rome, Vatican.

7-MS. De-Rossi, Parma.

P-MS. Oxford, Bodleian.

ב-MS. Bloch, Berlin.

$\aleph-M S$. Adler, Jewish Theological Seminary.

„-MS. Bamberger, Jewish Theological Seminary.

$$
\begin{aligned}
(\quad) & =\text { omission. } \\
{[\quad] } & =\text { addition. } \\
] & =\text { different reading. }
\end{aligned}
$$

